\title{
A Review of Using Green Technology in Civil Engineering
}

\author{
Mohammed Noori Hussein Alhashimi \\ Department of Civil Engineering \\ Iraq University College \\ Basra, Iraq
}

\begin{abstract}
Due to the evolution of life in the last century and the continuing development to the present time, in addition to the increase in the presence of factories and laboratories and modern means of transport and increase the requirements of living such as housing and work and the resources of consumption of food, water and energy. All these things led to a large pollution in the environment in which we live. And the increase in the consumption of fuel and energy will lead to an increase in the proportion of harmful substances that will be put in the environment as a result of the consumables we use in our daily lives. Hence, there is an urgent need to preserve the environment and to detoxify harmful substances and human waste. The term green technology refers to the use of healthy resources and clean energy sources that do not contain harmful residues when used. One of the areas in which green technology is involved is the engineering fields, especially structural engineering, so that waste recycling and its use for construction purposes can be achieved in addition to building environmentally friendly facilities. This paper presents a review of the use of green technology in the fields of civil engineering.
\end{abstract}

Keywords: Green Technology, Green Building, Waste Recycling Materials

\section{INTRODUCTION}

Green technology is an environmentally friendly technology that prevents pollution that harms human health and living organisms. This technology provides energy sources and alternative resources to sources and resources that cause damage to the environment. The world has large natural resources that can be used to produce green technology. Some of these resources have been fully depleted and others are still available. For instance - family unit batteries and hardware frequently contain unsafe synthetic concoctions that can dirty the groundwater after transfer, debasing our dirt and water with synthetics that can't be expelled from the drinking water supply and the nourishment crops developed on defiled soil. The dangers to human wellbeing are incredible. In this way, the need of great importance is that each financial specialist should think green. They should realize that green innovations and clean advances are great business. These are quickly developing markets with developing benefits. From the view purpose of purchasers, they ought to likewise realize that purchasing green developments can diminish their vitality charge and that green creations are regularly more secure and more advantageous items [1]. Green technology covers an expansive territory of generation and utilization advancements. The appropriation and utilization of green advances includes the utilization of ecological advances for checking and appraisal, contamination counteractive action and control, and remediation and rebuilding. Checking and evaluation innovations are utilized to gauge and track the state of the earth, including the arrival of common or anthropogenic materials of a hurtful sort. Aversion innovations maintain a strategic distance from the generation of earth dangerous substances or adjust human exercises in ways that limit harm to nature; it includes item substitution or the update of a whole creation process as opposed to utilizing new bits of gear. Control innovation renders unsafe substances innocuous before they enter the earth. Remediation and reclamation advancements exemplify techniques intended to enhance the state of biological systems, debased through normally instigated or anthropogenic impacts [1].

\section{GREEN TECHNOLOGY IN BUILDINGS}

Civil engineering projects can have noteworthy site-particular and combined effects on our environmental and social frameworks if not accurately arranged, outlined and executed[2]. In the region of manageability, there is an earnest 
need to apply advances and techniques that convey better and more reasonable execution in a way that is financially savvy. Feasible, versatile and mitigative ways to deal with environmental change, in the outline of framework are subsequently critical directing components [3]. Moderately couple of planners have so far investigated the transformative capability of environmental outline and have liked to stay unopinionated and unconcerned with the distributional effects of plan as they influence the wellbeing of people and biological communities [4]. Infrastructure components, for example, streets, water, sewage and stormwater can result in loss of basic biological systems and biodiversity. There is a need to make an eco-delicate framework configuration rating framework that empowers and advances the utilization of "gentler" outline arrangements. The rating of green structures assesses the ecological effects of structures however with little accentuations on the natural execution of structural building foundation. The proposed examine utilizes the idea of the green rating of green structures and makes a choice toolbox that evaluates the ecological effects of framework plan choices on advancement. By using enhanced earth benevolent looking for outline arrangements, this investigation intends to present ecologically well-disposed plan choices before the framework plan endorsement process [2].

\section{APPLICATION OF GREEN TECHNOLOGY IN CONSTRUCTION}

\subsection{Green technology for Low cost housing}

The construct of building houses or housing units requires a lot of money and this is because of the high prices of construction materials clearly. So it became difficult to provide housing units for millions of people at the time of rising prices, it was necessary to find an alternative to the construction materials to make this alternative is low cost and available. The procedure needs to choose based on nearby climatic condition and on the accessibility of neighborhood normal building materials/assets. There is a dire need to grow new building materials and advancements for minimal effort lodging in provincial territories. This requires the utilization of fitting and savvy building materials and advances in the development of abiding units. The utilization of bamboo as a fortifying material after reasonable treatment with economically accessible material like black-top is one of the answer for minimal effort lodging. The fundamental issue with utilizing bamboo as fortification instead of steel is that it ingests water what's more, swells and later on when it dries it lessens to its typical measure and from now on decreasing the quality of the bond between bamboo and concrete. Treatment of bamboo with some waterproof covering makes bamboo less powerless to dampness. In this manner irrelevant swelling and shrinkage of bamboo happens amid the relieving time of concrete [5].

\subsection{Blended Cement}

These are cements containing a high volume of one or more complementary cementing materials (CCM), such as coal fly ash, granulated slag, silica fume and reactive rice-husk ash. A large volume of $\mathrm{CO} 2$ is directly emitted during the cement manufacturing process (0.9 tonnes/tonne of clinker). Reduction in the quantity of clinker by substituting with CCM results in lesser $\mathrm{CO} 2$ emissions [5].

\subsection{Green technology for Road, Parking and Residential Construction}

low volume streets can be made penetrable so rain water goes into the asphalts and afterward gradually trickles into the ground water. This will likewise wipe out sprinkle of water when an auto moves amid light rains. Most fitting sort of asphalt is precast solid asphalt. For low volume streets, the sub base furthermore, base layers must be open reviewed granular layer which have great porousness. Treatment with concrete or bitumen can improve the quality of the granular layers for substantial movement [5].

\subsection{Buildings with low Carbon Pollution}

Disclosure of normal inorganic covers like pozzolanic materials brought about lime-pozzolanic (LP) cement and this made ready for the development of Portland cement in 1824 . Portland cement also, steel acquired progressive changes the development hones since early piece of twentieth century. Later on plastics furthermore, plastic items entered the development business. As we moved far from zero vitality materials to more present day materials for the development exercises, it wound up fast approaching to spend more vitality and normal assets. These cutting edge materials are vitality escalated and are pulled over long separations previously being utilized for development. With regards to carbon discharge decrease and the issue of a dangerous atmospheric devation, there is a need to focus on utilization of present day building materials with reference to (I) vitality power of materials, (ii) characteristic assets what's more, crude 
materials devoured, (iii) reusing and safe transfer what's more, (iv) effect on condition. Aimless utilization of common assets and vitality concentrated process for the building materials won't prompt supportable choices [5].

\section{ADVANTAGES AND DISADVANTAGES OF GREEN TECHNOLOGY}

1. Does not discharge anything negative into climate

2. Convey monetary benefits to specific zones

3. Need less maintenance

4. It is sustainable which means will never run out

5. Moderate the effects of a worldwide temperature alteration by diminishing $\mathrm{CO} 2$ outflows

The upside of utilizing environmentally friendly power vitality sources is that it must be spotless in this manner there is no release or harm into the earth or air. Furthermore, it is additionally replenishable rather than oil. What's more, efficient power vitality offices are troublesome on the wallet to assemble, it requests a lesser measure of upkeep in this manner it needs to spend some enormous money to work it. In addition, this may likewise make financial favorable circumstances to some specific regions and even create tourism industry. Indeed, even while these appear to be phenomenal, there are a rare sorts of people who accept there exists benefits to utilize such innovation. Setting up these offices moreover needs a lot of land so we may need to cut on farmland which clarifies what many are stressed over if more breeze generators must be set up. A second negative perspective is the reality huge numbers of the efficient power vitality sources can't generally be introduced in particular places of the earth [6][7]. Green procedures and innovation alludes to trying endeavours to enhance vitality effectiveness or decrease the contamination delivered by your home, business and general living propensities. The principle reason for this sort of procedures and innovation is to lessen the potential negative effect that vitality utilization and contamination can have on nature. While ecologically agreeable living is a positive perfect, there are a few conceivable weaknesses of Green procedures and innovation, for example, high executing costs, absence of data, no known elective compound or crude material sources of info, no known elective process innovation, vulnerability about execution effects, and absence of HR and aptitudes [7][8].

\section{CONCLUSION}

Green buildings can be constructed in simple and costeffective ways, in addition to the availability of the materials needed for their construction. Green buildings and ecofriendly buildings are more economical than the traditional lines that arise from the use of traditional materials. The conservation process is the result of recycling and use of waste for construction purposes.

\section{REFERENCES}

[1] Soni, G. D. (2015). "Advantages of green technology." International Journal of Research 3(9).

[2] Saroop, S. and D. Allopi (2012). Establishing a Green Rating System on Civil Engineering Infrastructure Projects. Abstracts of the 31st Southern African Transport Conference (SATC 2012), Citeseer.

[3] FIDIC, 2009. FIDIC State of the World Infrastructure Report 2009.

[4] Van Wyk, L. 2009. EcoBuilding: Towards an Appropriate Architectonic Expression, In Green Building Handbook for South Africa [online]. [Accessed 13 April 2011]. http://researchspace.csir.co.za/dspace/bitstream/10204/32 62/1/vanWyk1_2009.pdf

[5] Verma.I , Sohoni P and Verma.N . " application of Green Technology in Infrastructure" INTERNATIONAL JOURNAL OF SCIENTIFIC RESEARCH. Volume : 2 Issue : 2 Feb 2013.

[6] Sanjukta Banerjee et al. "Advantages of green technology" Recent Research in Science and Technology 2014, 6(1): 97-100.

[7] A. Iravani, I. Birjand, and M. Zohoori, "Advantages and disadvantages of green technology; goals, challenges and strengths," Int. J. Sci. Eng. Appl, vol. 6, p. e284, 2017.

[8] (Recent Research in Science and Technology 2014, 6(1): 97-100 ISSN: 2076-5061 Available Online: http://recentscience.com) 